\title{
ESTIMATION OF COOLING REQUIREMENT OF MAGNETS IN THE MULTI-CUSP PLASMA DEVICE
}

\author{
Nilesh Dama ${ }^{1}$, N. Ramasubramanian ${ }^{2}$ \\ ${ }^{1}$ Student, Mechanical Engineering, K. J. Somaiya College of Engineering, Mumbai, Maharashtra, India, \\ nmdnileshmdama@gmail.com \\ ${ }^{2}$ Scientist, Basic Sciences, Institute for Plasma Research, Gandhinagar, Gujarat, India
}

\begin{abstract}
The need for energy generation from clean sources like nuclear fusion has given rise to increased research in the Plasma and its characteristic properties. Multi-cusp Plasma Device installed at the IPR is one of the device used to study the plasma characteristics wherein quiescent plasma is generated. An optimized design of water cooling system is necessary to ensure the removal of heat losses and keep the electromagnets of the plasma device under the safe operating conditions of temperature and thermal stresses by passage of flow of water, thereby increasing the life cycle of the device. The project focuses on the fluid flow analysis for the heat transfer of generated heat in the magnet due to the continuous supply of electricity. The aim of this project is to determine the performance and working attributes of the cooling system used. The design and evaluation of the cooling system are executed on the basis of analytical calculations and actual experimentation work on the device.
\end{abstract}

Key Words: Chiller requirement, cooling requirement, electromagnet cooling, fluid flow analysis, Multi-cusp plasma device, pressure drop, pump requirement, water cooling.

\section{INTRODUCTION}

The basic aim of Multi-Cusp Plasma Device is to confine contact ionized (tungsten surface) cesium ions in a multiline cusp magnetic field and do its characterization. The expected result of this plasma device is the generation of a 'text book' like ideal plasma, with $\mathrm{Te} \sim \mathrm{Ti}$, really quiescent, with only 'natural' fluctuations [1]. The device would be used to identify the real thermodynamic fluctuations and its sources. The plasma generated would then be disturbed with energy and particles and will be used to study the linear and non-linear evolving phenomena of the plasma. The problem arises due to drift of low frequency electrostatic waves which propagates perpendicular to direction of $B$ and $\mathrm{dn}$. The solution is provided by Cusp fields which produce B 0 in the centre. Vacuum chamber, Magnet assembly, hot cathode ionizer, cesium vapor oven and probe diagnostics are the major subsystems of this Multi-cusp Plasma Device. This paper basically focuses on the Magnet part of the device. Electromagnet with high Curie temperature soft-core material is required for the Plasma device.

An electromagnet is a type of magnet in which the magnetic field is produced by an electric current. The magnetic field disappears when the current is turned off. Electromagnets usually consist of a large number of closely spaced turns of wire that create the magnetic field. The wire turns are often wound around a magnetic core made from a ferromagnetic material such as iron; the magnetic core concentrates the magnetic flux and makes a more powerful magnet. Electromagnets are made with Vacoflux-50 (alloy of iron $50 \%$ and cobalt $50 \%$ ) core material and copper pipes are used as winding for water cooling. The main advantage of an electromagnet over a permanent magnet is that the magnetic field can be quickly changed by controlling the amount of electric current in the winding. However, unlike a permanent magnet that needs no power, an electromagnet requires a continuous supply of current to maintain the magnetic field. This continuous supply of current may overheat the magnet. The electrical power which is dissipated in the coils has to be removed from the magnets otherwise overheating can seriously damage the coil insulation and cause short circuits between the coil conductor and the surrounding equipment which is usually on ground potential. Therefore, a cooling arrangement is a must for the electromagnet. The driving force for the transfer of heat is the difference in temperature between the two media. Coils that are pulsed infrequently for short periods may not need to be cooled. The given report briefs about the available types of cooling and it gives a proper explanation for selection of particular type of cooling system. It provides a detailed explanation about the apparatus and the equipment required to perform a successful experiment to determine the important parameters for the cooling arrangement. So, the problem is basically a thermo hydraulics problem. The velocity of the flowing water should be sufficiently large enough(less than $5 \mathrm{~m} / \mathrm{s}$ ) to ensure a turbulent flow but low enough to avoid erosion and vibration. The experiment focuses on finding values of water cooling system's parameters like max flow rate of water required to maintain magnet at room temperature, pressure drop, temperature difference of inlet and outlet water, water quality to be used, etc. using theoretical calculations and by validating it with experimental results. 


\section{TYPES OF COOLING ARRANGEMENT}

As per Zickler T, basically there are two types of cooling methods to cool the magnet [2].

\subsection{Air Cooling}

It is also referred to as dry cooling. Air cooling by natural convention is suitable only for low currents and low current densities of up to $2 \mathrm{~A} / \mathrm{mm}^{2}$. Thus it would limit the use of magnet to a moderate value field strength which is not at all desirable

\subsection{Water Cooling}

Water cooling is also known as wet cooling. Direct and indirect cooling are the two methods of water cooling. The latter is of minor importance and rarely used, although it has the advantage that normal tap water can be used as a coolant, which does not require cooling plants with water treatment for the supply of demineralized water. In the absence of such infrastructure, indirect cooling should be considered as a possible alternative, even though it implies a more complex coil design.

The current density in direct water cooled coils can be typically as high as $10 \mathrm{~A} / \mathrm{mm}^{2}$. It is a good compromise assuring a high level of reliability during operation and compact coil layout. Although current densities of $80 \mathrm{~A} / \mathrm{mm}^{2}$ can be attained for specific applications, it is not recommended for standard magnets because the reliability and lifetime of the coils is significantly reduced. High currents require a sophisticated cooling circuit design with prevention that high velocity of flowing water to carry away the heat losses does not corrode or erode away the material through which the water is flowing. Standard water cooled coils are wound from rectangular or square, copper or aluminium, conductor with a centre cooling duct for demineralized water Since, water quality is essential for the performance and reliability of the coil, the following typical water properties should be guaranteed [3]:

* Water resistivity higher than $5 * 10^{6} \Omega$.cm

* pH value between 6 and 6.5

* Dissolved oxygen below $0.1 \mathrm{ppm}$

Since, in our system we have to pass a current of about 160A through the magnet coils for a long duration, it can be easily made out that air cooling won't suffice the need and water cooling has to be used.

Once through cooling system, Open recirculating system and closed recirculating system are the different types of available water cooling arrangements.

In our Multi-cusp Plasma Device, direct water cooling is used. The heated water after taking heat losses from the magnet passes into the chiller (cooler) and the same water after being cooled in the chiller is reused again to cool the magnet. It is thus Open recirculating system where there is no evaporation of the water because the chiller lid is closed and thus there are no treatment related problems.

\section{EXPERIMENTAL SETUP}

There are 6 magnets at $20 \mathrm{~cm}$ radius installed on the Multicusp Plasma Device. The experiment was initially carried out on 1 magnet and the results were obtained for 6 magnets by assuming that they will show same characteristic behaviour. Each magnet has a double pancake coil winding. It has 8 pancakes (coils). Each pancake winding has 5 turns in 1 direction (say clockwise) and 5 turns in other direction, thereby accounting to a total of $N=10$ turns. At the centre of the magnet is a soft core material called Vacoflux 50. The purpose of the core material is just to shape the magnet field generated, it doesn't play any role in increasing the strength of the generated magnetic field. This profiling is done to reduce the edge saturation effects. The conductor coil is made of copper material. Coil basically has elliptical kind hollow conductor profile for carrying water to cool the coil. Insulation is provided to prevent short-circuit or any accident. Leads are provided on each coil winding for applying current. Leads are all connected with screws to connect coils in series electrically. Hydraulically, there are 2 available outlet pipes (bore in the copper conductor coil is referred to as the pipe) in each pancake winding. So in total we have 16 pipes for water flow. Cooled water enters into these pipes after the chilled (cooler) water is pumped by the pump. A header is provided at the top which distributes the entire pressurized flow of cooling water into 8 small different pipes which enter into each coil winding of the magnet as the inlet. Similarly, 8 outlets of the coils of a magnet are again input to another header called O/P header from which a single pipe then goes to the cooler carrying along heated water in it. PU pipes are used to connect magnet coil pipes, with the inlet and outlet pipes connected to the header. Valves are provided just near the inlet and outlet of the magnet coil pipe to control the flow of water as required. A DC power supply is used to provide current of up to $160 \mathrm{~A}$ to the magnet. A single wire has the current capacity of 50A, so 3 wires were used to connect the terminals of the power supply and magnet current leads. The temperature of the cold water and the outlet heated water is measured using a thermocouple connected to digital multimeter (DMM). The mass of the water flowing through magnet is estimated by using a stop watch and measuring beaker arrangement. The specific characteristic values for water were taken from NIST website [4], [5]. Various properties, designs, technical data were obtained from [6] and the website was also used for calculations along with Matlab, Excel software. [7] gives various steps to design the cooling system.

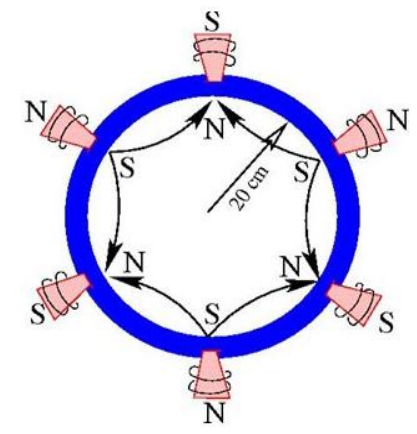

Fig -1a: Magnet Assembly

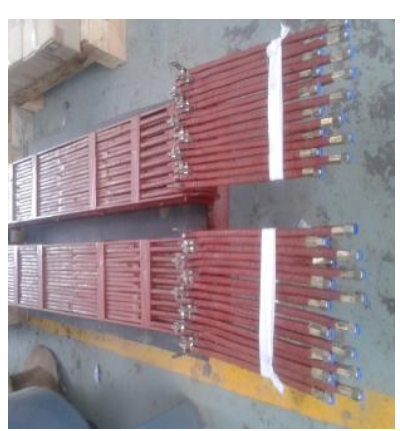

b) Pipes of magnet 

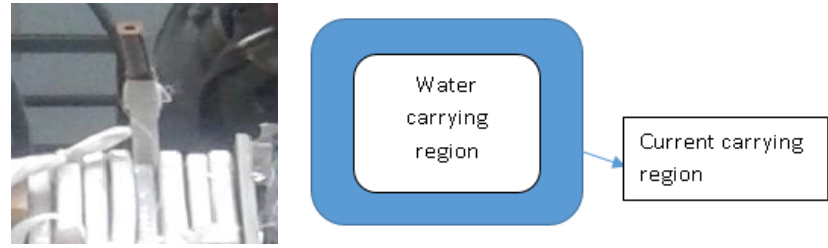

Fig -2: Hollow conductor pipe profile for coolant flow

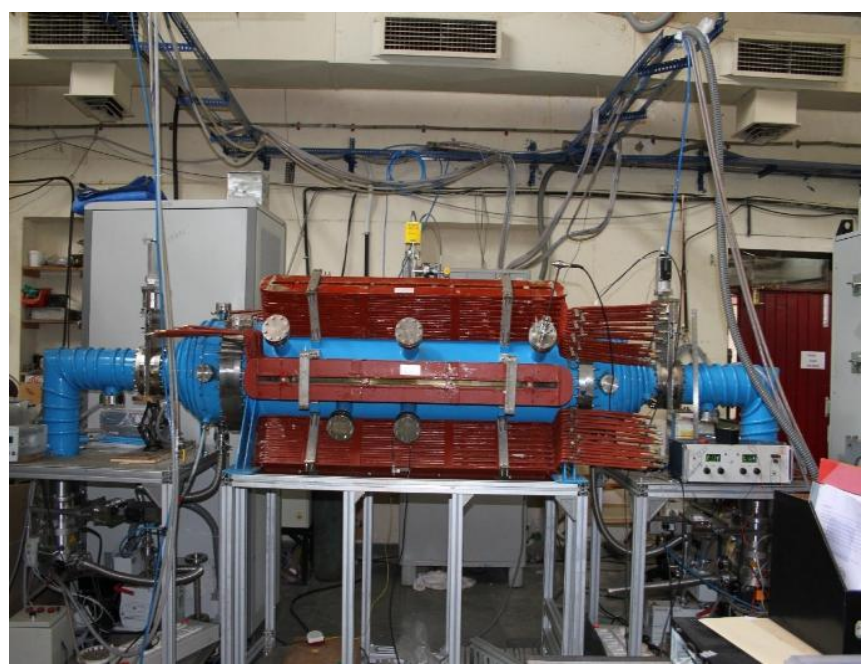

Fig -3: Multi-cusp Plasma Device

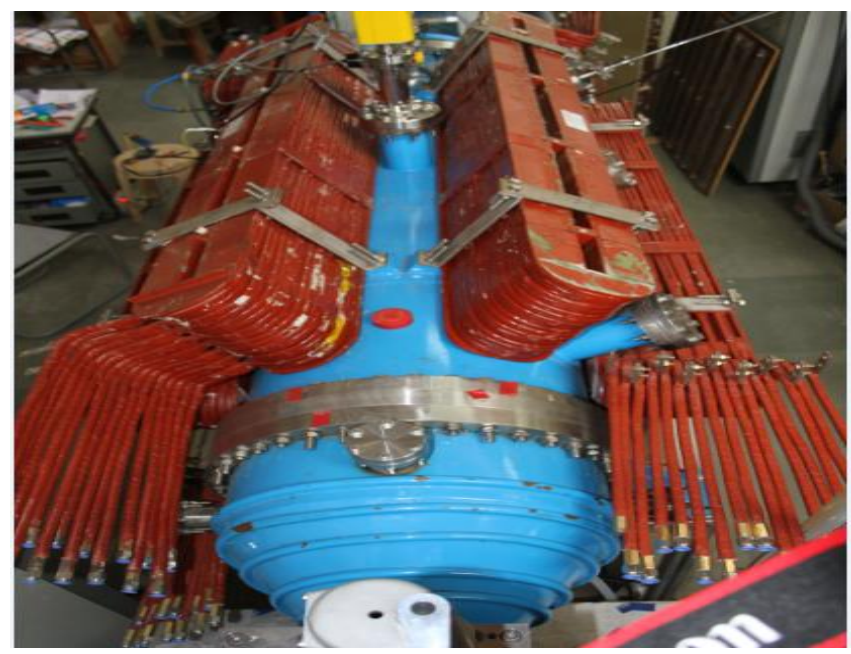

Fig -4: Magnets and vacuum chamber

\section{POSSIBLE METHODS TO CARRY OUT EXPERIMENT}

\subsection{Calculations by finding pressure drop $(\triangle p)$ :}

Heat loss is equal to enthalpy change of inlet and outlet. Enthalpy is a function of pressure and temperature. So if we know inlet and outlet pressure and temperature, we can perform the experiment and optimize the cooling requirement of the system. Pressure change can be measured using a normal dial pressure gauge at inlet and outlet find out $\Delta p$. As the pressure drop is related to the velocity of the flow, this pressure drop will in turn give the velocity of the flowing water. Flow rate $\stackrel{\circ}{m}$ can be calculated from the velocity thus obtained. This flow rate can also be used to find out heat load (heat loss) on the magnet. In this experiment, mass flow of the water $\stackrel{\circ}{m}$ should be changed and different readings should be noted accordingly for a given current flow. Further change the current and repeat the above procedure.

$\Delta p$ can also be found out using a Differential pressure gauge or a U-tube Manometer.

\subsection{Calculations by Finding Mass Flow Rate ( $m$ ):}

A flowmeter or rotameter would directly give the flow rate of water flowing through the magnet. This flow rate should then be compared with theoretically required mass flow rate of water. Using formulas we can find out other important parameters. Here, the readings should be taken for different values of $\Delta T$ by adjusting the flow for a particular $\Delta T$ and noting that flow rate reading perform other calculations for cooling system design

\subsection{Hydraulic and Electrical connections:}

There are $\mathrm{n}$ number of ways to hydraulically connect the given magnet pipes to ensure the cooling of the magnet. We can test each single coil's water requirement by passing different current. Various parallel and series combination of pipes can be done for the efficient cooling.

The experiments were performed for:

* Only $1^{\text {st }}$ coil with a current passage of $100 \mathrm{~A}$

* 1,2,3 coils connected in parallel and a current passage of $100 \mathrm{~A}$

* 1,3,5,7 coils connected in parallel and a current of $100 \mathrm{~A}$ is passed

* 4 parallel groups of 2 coils in series (i.e $1,2+3,4+5,6$ $+7,8)$. Here outlet of 1 is connected to the inlet of 2 , Outlet of 3 to the inlet of 4 , and so on. Thus effectively we get 4 inlet pipes and 4 outlet pipes in this hydraulic arrangement. The readings here were taken for $100 \mathrm{~A}$ as well as $150 \mathrm{~A}$

* Last option is to connect all 8 coils in a parallel manner. This would also ensure proper cooling as water flows through each pipe. But the pressure drop in this case will be low as there will be resistance of only 1 coil. Also there would be requirement of more piping in this case and to control 8 inlet and 8 outlet valves of 1 magnet would be a difficult task

\subsection{Experiment Procedure Overview:}

[1]. Calculate heat loss (heat load)

[2]. Calculate flow requirement

[3]. Find flow velocity

[4]. Find out pressure drop

[5]. Calculate pump capacity required

[6]. Chiller required

\section{OBSERVATIONS}

From the tests it was found out that making 4 parallel groups of 2 coils in series was the best combination for cooling the magnet with minimum water requirement. Passing the water through 4 alternate coils $(1,3,5,7)$ is also not advisable as the water here wouldn't cool the coil numbers $(2,4,6,8)$ and thus it would not result in the proper cooling of the magnet. 
Table -1: Parameter values

\begin{tabular}{|l|c|l|}
\hline $\begin{array}{l}\text { Resistivity of copper } \\
\text { pipe }\end{array}$ & $\sigma$ & $1.68 \times 10^{-8} \Omega . \mathrm{m}$ \\
\hline $\begin{array}{l}\text { Dimension of water } \\
\text { carrying region of pipe }\end{array}$ & $w, h$ & $5.2 \mathrm{~mm}, 3.2 \mathrm{~mm}$ \\
\hline Hydraulic diameter & $D_{h}$ & $3.96 \mathrm{~mm}$ \\
\hline Area for water flow & $A_{f}$ & $16.64 \mathrm{~mm}^{2}$ \\
\hline Outer area of pipe & $A_{o}$ & $59.84 \mathrm{~mm}^{2}$ \\
\hline $\begin{array}{l}\text { Area of current carrying } \\
\text { region }\end{array}$ & $A=\left(A_{o}-A_{f}\right)$ & $43.2 \mathrm{~mm}^{2}$ \\
\hline Specific heat of water & $C_{p}$ & $4.187 \mathrm{~kJ} / \mathrm{kg} . \mathrm{K}$ \\
\hline Density of water & $\rho$ & $996.69 \mathrm{~kg} / \mathrm{m}^{3}$ \\
\hline $\begin{array}{l}\text { Viscosity of water at } \\
20^{\circ} \mathrm{C}, 2 \text { bar }\end{array}$ & $\mu$ & $10.016 \times 10^{-4} \mathrm{~Pa} . \mathrm{s}$ \\
\hline
\end{tabular}

$l:$ length of pipe in consideration

$\dot{m}$ : mass flow rate of water

$\Delta T$ :rise in temperature $=$ outlet temperature - inlet temperature $v$ : velocity of water

$R_{g}:$ Reynolds number

$f:$ friction factor

Table -2: Pump and cooler specifications

\begin{tabular}{|l|l|}
\hline Pump Specifications & Cooler specifications \\
\hline Kirloskar Brothers & $\begin{array}{l}\text { Plue Star } \\
\text { PHASE,230V,50Hz }\end{array}$ \\
\hline TYPE : KDS- 225+ & CURRENT :7A F.L.A \\
\hline Sr.NUMBER:ATABXF0290 & $\begin{array}{l}\text { POWER CONUMPTION } \\
\text { 1550 Watts }\end{array}$ \\
\hline SIZE : 50×40 I/P kW: $: 22$ \\
HEADIGERANT:R-22 \\
950 grams
\end{tabular}

Table -3: Details of magnet and its rated values

\begin{tabular}{|c|c|}
\hline No of magnets & 6 \\
\hline Total no of pancake coil windings & $\begin{array}{c}8 \text { pancake double } \\
\text { winding }\end{array}$ \\
\hline Number of turns in each pancake $N$ & $10(5+5)$ \\
\hline $\begin{array}{c}\text { Max current to be passed in each } \\
\text { magnet and time duration }\end{array}$ & $\begin{array}{c}160 \mathrm{~A} \text { and continuous } \\
\text { supply }\end{array}$ \\
\hline Max allowable temperature & $150^{\circ} \mathrm{C}$ \\
\hline $\begin{array}{c}\text { Max pressure of water allowed } \\
\text { through inlet }\end{array}$ & $10^{\text {bar }}$ \\
\hline Operating pressure & 2.2 bar $(22 \mathrm{~m} \mathrm{Head})$ \\
\hline Water used & DM water \\
\hline
\end{tabular}

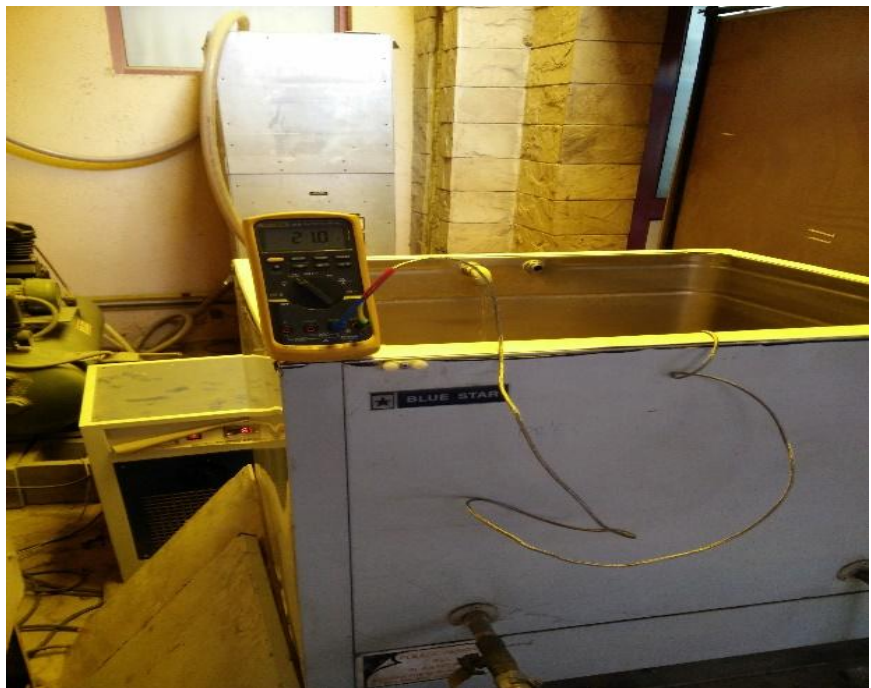

Fig -5: Temperature reading shown by DMM

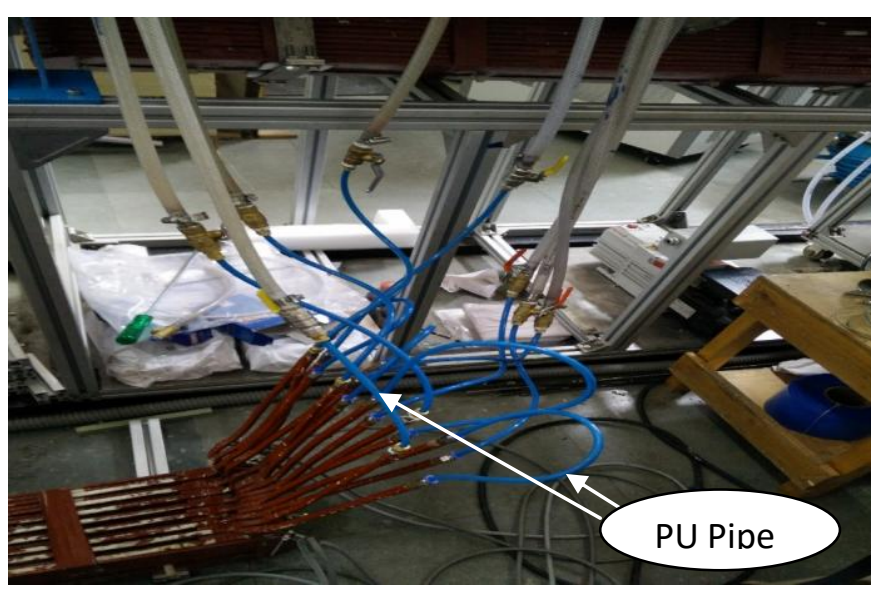

Fig -6: Hydraulic connections of a magnet
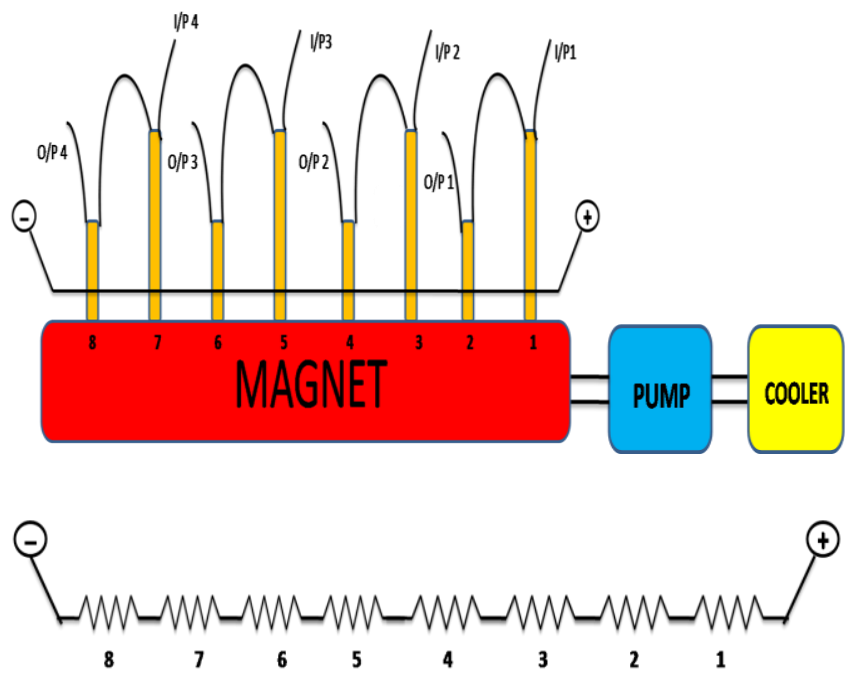

Fig -7: Layout diagram of project setup 
Table -4: For Current $I=100.3 \mathrm{~A}$, Voltage $V=9.6 \mathrm{~V}$

\begin{tabular}{|c|c|c|c|c|c|}
\hline \multicolumn{3}{|c|}{$\begin{array}{c}\text { Water } \\
\text { Quantity }\end{array}$} & \multirow{2}{*}{$\begin{array}{l}\text { Outlet } \\
\text { Temper } \\
\text { ature } \\
\left(\text { in }^{\circ} \mathrm{C}\right)\end{array}$} & \multirow{2}{*}{$\begin{array}{l}\text { Inlet } \\
\text { Temper } \\
\text { ature } \\
\left(\text { in }^{\circ} \mathrm{C}\right)\end{array}$} & \multirow[t]{2}{*}{$\Delta T$} \\
\hline $\begin{array}{l}\text { (in } \\
\text { ml) }\end{array}$ & $\begin{array}{l}\text { (in } \\
\mathrm{kg} / \mathrm{s} \text { ) }\end{array}$ & $\begin{array}{l}\text { (in } \\
\text { lpm) }\end{array}$ & & & \\
\hline 1770 & 0.059 & 3.54 & 30 & 23.2 & 6.8 \\
\hline 1820 & 0.0606 & 3.64 & 29.8 & 21.7 & 8.1 \\
\hline 1840 & 0.0613 & 3.68 & 29.7 & 22.4 & 7.3 \\
\hline 1800 & 0.06 & 3.6 & 29.6 & 22.4 & 7.2 \\
\hline 1820 & 0.0606 & 3.64 & 29.5 & 21.8 & 7.7 \\
\hline
\end{tabular}

Table -5: For Current $I=150.1 \mathrm{~A}$, Voltage $V=14.4 \mathrm{~V}$

\begin{tabular}{|l|c|c|c|c|c|}
\hline \multicolumn{3}{|c|}{$\begin{array}{l}\text { Water } \\
\text { Quantity }\end{array}$} & $\begin{array}{l}\text { Outlet } \\
\text { Temper } \\
\text { ature } \\
\text { (in }{ }^{\circ} \mathrm{C} \text { ) }\end{array}$ & $\begin{array}{l}\text { Inlet } \\
\text { Temperat } \\
\text { ure } \\
\text { (in }{ }^{\circ} \mathrm{C} \text { ) }\end{array}$ & $\Delta T$ \\
\cline { 1 - 2 } $\begin{array}{l}\text { (in } \\
\text { ml) }\end{array}$ & $\begin{array}{l}\text { (in } \\
\mathrm{kg} / \mathrm{s})\end{array}$ & $\begin{array}{l}\text { (in } \\
\text { lpm) }\end{array}$ & & & \\
\hline 1800 & 0.06 & 3.6 & 32.7 & 21.2 & 11.5 \\
\hline 1850 & 0.0616 & 3.7 & 32.9 & 22.1 & 10.8 \\
\hline 1850 & 0.0616 & 3.7 & 33 & 21.7 & 11.3 \\
\hline 1850 & 0.0616 & 3.7 & 32.9 & 21.6 & 11.3 \\
\hline 1870 & 0.0623 & 3.74 & 33 & 21.9 & 11.1 \\
\hline 1830 & 0.061 & 3.66 & 33.2 & 22.2 & 11.0 \\
\hline
\end{tabular}

\section{CAlculations}

Theoretical calculations for $I=100.3 \mathrm{~A}, \quad V=9.6 \mathrm{~V}$ for 1 magnet

Let us denote grouping of $1^{\text {st }}$ and $2^{\text {nd }}$ coil in series as 1 st connection

Similarly $3^{\text {rd }}-4^{\text {th }}$ coil in series represent 2 connection

Resistance of 1 coil,

$$
R=\frac{\sigma \cdot l}{A}
$$

$R=\left(1.68 \times 10^{-8} \times 30\right) /\left(43.2 \times 10^{-6}\right)=0.011667 \Omega$

$$
R \text { of } 2 \text { coils }=R_{\text {lconnection }}
$$

$R$ of 2 coils $=2 \times 0.011667=0.023334 \Omega$

Also, Resistance of 8 coils ( 4 connections),

$$
R_{\text {series }}=V / I
$$

$R_{\text {series }}=9.6 / 100.3=0.0957 \Omega$

$R_{\text {lconnection }}=0.0957 / 4=0.0239282 \Omega$

Heat load $=I^{2} \cdot R_{\text {lconnection }}$

Heat load $=100.3 * 0.02334=234.8025006 \mathrm{~W}$

$\mathrm{I} / \mathrm{P}$ Power $=V I$ for 8 coils

$$
\begin{aligned}
& =\left[\left(V_{1}+V_{2}\right)+\left(V_{3}+V_{4}\right)+\left(V_{5}+V_{6}\right)+\left(V_{7}+V_{8}\right)\right] * I \\
& =\left[V_{1} \text { connection }+V_{2} \text { connection }+V_{3}\right. \text { connecton }
\end{aligned}
$$

$+V_{4}$ connection $]^{*} I$

$$
=9.6 * 100.3 \text { for } 8 \text { coils }
$$

$=962.88 \mathrm{Watt}$

Water required:

$$
\text { Heat load } / \text { Heat loss }=\stackrel{\circ}{m} . \text { Cp. } \Delta T
$$

$234.8025006=\stackrel{\circ}{m} \times 4.187 \times(29.72-22.3)$

$\stackrel{\circ}{m}=7.5578079 \times 10^{-3} \mathrm{~kg} / \mathrm{s}$

$\stackrel{\circ}{m}=0.045346847 \mathrm{lpm}$ or $\mathrm{kg} / \mathrm{min}$

For 1 connection,

$\stackrel{\circ}{m}=\rho . A_{f} v$
$7.5578079 \times 10^{-3}=996.69 \times 1.64 \times 10^{-5} \times v$

$v=0.45570356 \mathrm{~m} / \mathrm{s}$

$$
R_{e}=\frac{\rho \cdot v \cdot D_{h}}{\mu}
$$

$R_{e}=\left(996.69 \times 0.45570356 \times 3.96 \times 10^{-3}\right) /\left(10.016 \times 10^{-4}\right)$ $=1795.7397$

$$
f=64 / R_{e}
$$

$f=64 / 1795.7397=0.0356399$ (considering laminar flow)

$$
\Delta \mathrm{p}=\frac{f \cdot l \cdot \rho \cdot v^{2}}{2 \cdot D_{h}}
$$

$\Delta p=(0.0356399 * 60 * 996.69 * 0.45570356) /\left(2 * 3.96 * 10^{-3}\right)$ $=1.2263235 \mathrm{bar}$

$\Delta p$ will be same for all the four connections, i.e, same for the entire magnet

Pump Capacity:-

Pump capacity required for proper water flow in 1 magnet:

$$
\stackrel{\circ}{M}=4 \times \stackrel{\circ}{m}
$$

$\stackrel{\circ}{M}=0.0302312316 \mathrm{~kg} / \mathrm{s}=1.81387389 \mathrm{lpm}=$ mass flow rate for 1 magnet

Pump capacity to provide water flow in 6 magnets:

$$
\stackrel{\circ}{\text { total }}=6 \times \stackrel{\circ}{M}
$$

$\stackrel{\circ}{\text { total }}=10.88324334 \mathrm{lpm}=$ mass flow rate for all 6 magnets Chiller Capacity:-

Chiller capacity is ideally taken as $30 \%$ more than heat loss So, for 1 connection $=1.3 \times$ Heat loss $=1.3 \times$ $234.8025006=305.24325 \mathrm{~W}$

For 1 magnet $=4 \times 1$ connection $=1220.73003 \mathrm{~W}$

For 6 magnets $=4 \times 1$ magnet $=7325.838 \mathrm{~W}$

Thus, Chiller should be able to remove $7325.838 \mathrm{~W}$ of heat from the total hot water coming out of 6magnets to make it cool again for entry to inlet of magnet

\section{GRAPHS}

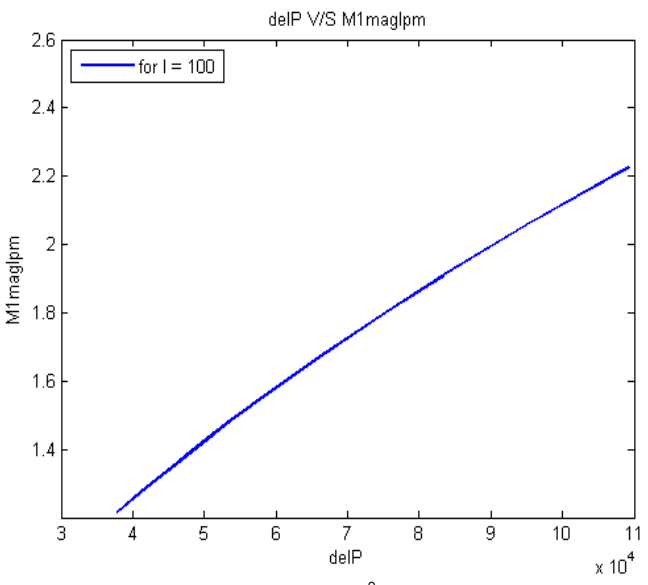

Chart -1: $\Delta p$ vs $\stackrel{\circ}{ }$ for $I=100 \mathrm{~A}$ 


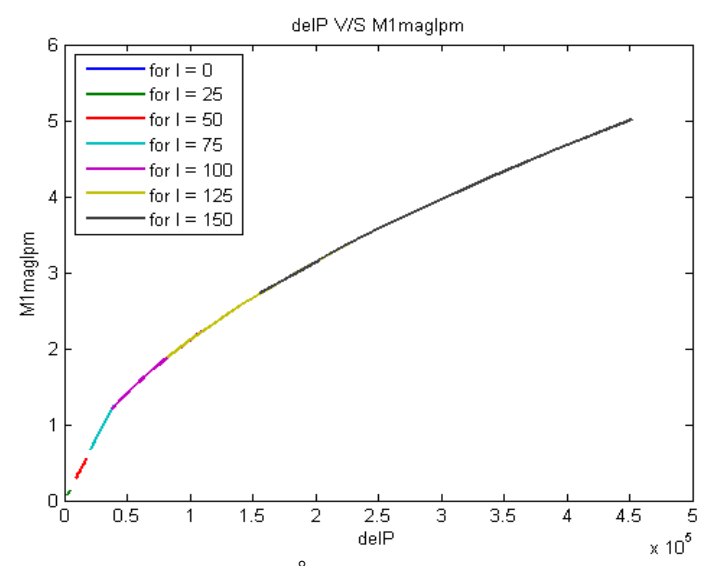

Chart -2: $\Delta p$ vs $\stackrel{\circ}{\text { for various current values }}$

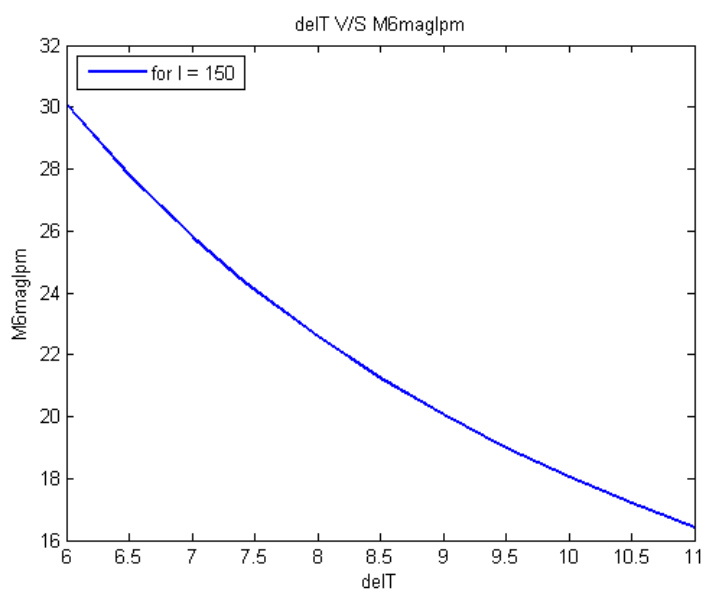

Chart -3: $\Delta T$ vs $\stackrel{\circ}{\text { total }}_{\text {for } I=150 \mathrm{~A}}$

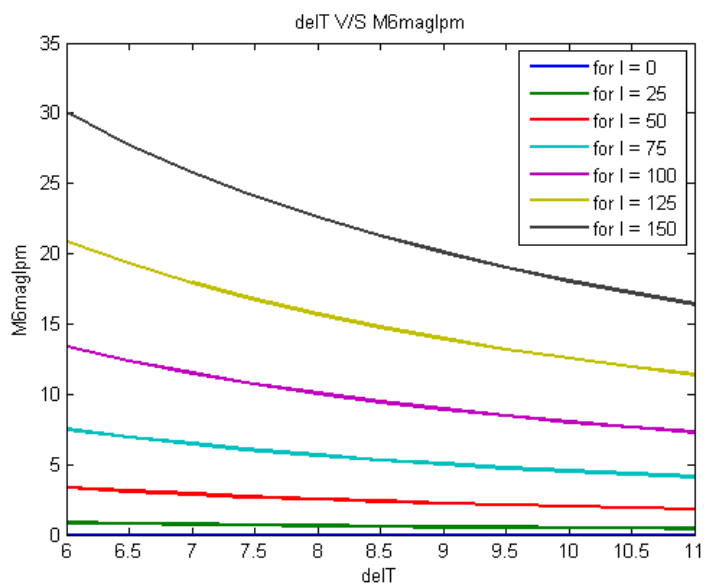

Chart -4: $\Delta T$ vs $\stackrel{\circ}{\text { total }}_{\text {for various current values }}$

\section{RESULTS AND DISCUSSION}

Chart 1 shows that mass flow requirement for a magnet will increase with pressure drop. Chart 2 successfully shows that more water has to be passed per second to cool the magnet when higher current like $I=150 \mathrm{~A}$ is passed through it. Chart 3 shows that mass flow requirement of water will decrease with increasing $\Delta T$. As per chart 4 , theoretically $\dot{M}_{\text {total }}$ (flow requirement for all six magnets) should decrease with increasing $\Delta T$. Also it suggests that for higher current higher

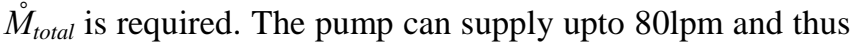
theoretical requirements can be easily met. Thus all graphs are valid with our calculations and understanding of the cooling requirement. (9) shows the friction factor value assuming laminar flow, however when the current is increased the flow enters the transition region and friction factor at that stage is calculated using explicit formulae and the charts are plotted accordingly [8].

Ohmic Heating: Since the magnetic field is proportional to the product $N I$, the number of turns in the windings $N$ and the current $I$ can be chosen to minimize heat losses, as long as their product is constant. Since the power dissipation increases with the square of the current but only increases approximately linearly with the number of windings, the power lost in the windings can be minimized by reducing $I$ and by increasing the number of turns $N$ proportionally or using thicker wire to reduce the resistance [9].

Heat flow resistance of the cooling water depends on equipment geometry, flow velocity, viscosity, specific heat of fluid and thermal conductivity of coolant. Another comment, in general, is that more surface area of wire contact with water improves heat transfer.

We assume a good heat transfer from conductor to coolant, with the temperature of the inner surface of the conductor equal to that of coolant and that conductor is isothermal over its cross-section. Typically, the designer will allow for a $5^{\circ} \mathrm{C}$ to $8^{\circ} \mathrm{C}$ temperature rise over the system. Although magnet is safe till $150^{\circ} \mathrm{C}$, we have to try limiting it to around $60^{\circ} \mathrm{C}$. A large proportion of the total pressure drop will come from pipe fittings - such as elbows and valves. Ensure that the hydraulic calculation considers pipe fittings. Often, the hydraulics has to be calculated before the pipe runs are fixed.

A poor quality of water might lead sooner or later to failures like electrical short circuits and leaks in the water circuits due to corrosion and erosion effects. Filters must be installed in the circuits close to the magnet to prevent unwanted contaminants and impurities from flowing through the magnet.

There was no Regulator at the pump outlet and thus flow could not be varied while performing the experiment. Further experiment can be performed after installing a regulator or flow control valve just after the pump outlet. Readings should be taken by varying $\stackrel{m}{ }$ till the pressure drop or temperature rise remains the same. This would give us the exact value of $\stackrel{\circ}{m}$ required.

A T-structure should be installed at pump outlet which would direct unwanted flow back to cooler without creating a backflow or back pressure on the pump while controlling flow through a valve.

Heat loss for 1 connection $=\stackrel{\circ}{m} \cdot C_{p} \cdot \Delta T=(0.06 / 4) \times 4.187 \times 7$ $=439.63 \mathrm{Watt}$

Theoretically, heat loss $=234.802 \mathrm{~W}$. 
This error in heat loss occurred as the temperature reading was taken at the cooler inlet and cooler outlet. From the graphs also it can be seen that if $\stackrel{\circ}{m}$ increases, $\Delta T$ decreases. Experimentally, mass flow rate was greater than theoretical value, so $\Delta T$ has to decrease experimentally to around $4.5^{\circ} \mathrm{C}$ from $7.5^{\circ} \mathrm{C}$. This happened when readings were again taken just near the magnet inlet and outlet.

Corrected experimental reading is

Heat loss for 1 connection $=\stackrel{\circ}{m} \cdot C_{p} \cdot \Delta T=(0.06 / 4) \times 4.187 \times 4.5$ $=282.62 \mathrm{~W}$

$282.62-234.802=57.818 \mathrm{~W}$ energy is the energy which is gained from the surroundings and due to other unaccounted losses. The readings should therefore be taken just near the magnet inlet and outlet pipes.

$$
\text { Power of pump }=\rho . g \cdot Q \cdot H
$$

Given pump is of $2 \mathrm{hp}$. Let us check whether $0.5 \mathrm{hp}$ pump KDS0510 with head of $10 \mathrm{~m}$ would suffice the need from the specifications available of the kirloskar pumps [10]

Its capacity is $0.94 * 60=56.41 \mathrm{pm}$. With around $50 \%$ efficiency it could provide upto $281 \mathrm{pm}$

This pump is sufficient. But to maintain a safeside we may select $1 \mathrm{HP}$ pump

1. KDS116+ with head of 14 or $16 \mathrm{~m}$ which will provide $3.62,3 \mathrm{lps}$

2. KDS $123+$ with head of 14 or $16 \mathrm{~m}$

\begin{tabular}{|c|c|c|c|c|c|c|c|c|c|c|c|c|c|c|c|c|c|c|c|c|}
\hline \multirow{3}{*}{ PUMP MODEL } & \multirow{2}{*}{\multicolumn{2}{|c|}{$\begin{array}{l}\text { POWER } \\
\text { RATING } \\
\end{array}$}} & \multirow{2}{*}{\multicolumn{2}{|c|}{$\begin{array}{c}\text { PIPE } \\
\text { SIZE (mm) }\end{array}$}} & \multicolumn{15}{|c|}{ TOTAL HEAD IN METRES } & \multirow{3}{*}{ 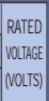 } \\
\hline & & & & & 6 & 8 & 10 & 12 & 14 & 16 & 18 & 20 & 22 & 24 & 26 & 28 & \begin{tabular}{|l|l|}
30 & 32 \\
\end{tabular} & 34 & \begin{tabular}{|l|l|}
36 & 40 \\
\end{tabular} & \\
\hline & $\mathrm{kW}$ & $\mathrm{HP}$ & SuC. & DEL. & \multicolumn{15}{|c|}{ CAPACITY IN UTRES PER SECOND } & \\
\hline KDSO510 & 0.37 & 0.5 & 50 & 40 & 3.37 & 2.62 & 0.94 & & & & & & & & & & & & & 415 \\
\hline KDSGMC 112 & 0.75 & 1.02 & 50 & 50 & 6.9 & 5.5 & 3.9 & 2.0 & & & & & & & & & & & & 415 \\
\hline KDSIGAC116++ & 0.75 & 1.02 & 50 & 40 & 5.35 & 5.0 & 4.63 & 4.2 & 3.62 & 3.0 & 2.0 & & & & & & & & & 415 \\
\hline KDSIGMC 123+ & 0.75 & 1.02 & 32 & 25 & & & 4.0 & 3.6 & 3.2 & 2.65 & 2.2 & 1.6 & 0.9 & & & & & & & 415 \\
\hline KDSIGMC 128+ & 0.75 & 1.02 & 25 & 25 & & & & & 1.9 & 1.82 & 1.72 & 1.57 & 1.37 & 1.1 & 0.77 & 0.4 & & & & 415 \\
\hline KDSGMC 134 & 0.75 & 1.02 & 25 & 25 & & & & & & 1.66 & 1.59 & 1.5 & 1.38 & 1.24 & 1.06 & 0.87 & 0.660 .4 & & & 415 \\
\hline KDSGGMC $1.514+$ & 1.10 & 1.5 & 50 & 50 & & 8.5 & 7.25 & 5.75 & 3.6 & & & & & & & & & & & 415 \\
\hline KDSGGNC $1.522++$ & 1.10 & 1.5 & 50 & 40 & & 6.35 & 5.95 & 5.55 & 5.1 & 4.5 & 3.9 & 3.1 & 1.8 & & & & & & & 415 \\
\hline KDSGGUC 1.525+ & 1.10 & 1.5 & 50 & 40 & 2.55 & 2.55 & 2.52 & 2.48 & 2.4 & 2.34 & 2.22 & 2.12 & 1.97 & 1.82 & 1.6 & 1.32 & & & & 415 \\
\hline KDSIGUC 1.540 & 1.10 & 1.5 & 32 & 25 & & & & & & & & & 20 & 1.87 & 1.74 & 1.59 & 1.451 .3 & 1.1 & 0.90 .64 & 415 \\
\hline KDS 212+ & 1.5 & 2 & 80 & 80 & 14.1 & 12.4 & 10.5 & 7.5 & & & & & & & & & & & & 415 \\
\hline KDS.216++ & 1.5 & 2.0 & 65 & 50 & & 11.0 & 10.0 & 8.8 & 7.15 & 4.0 & & & & & & & & & & 415 \\
\hline KDS.225++ & 1.5 & 2.0 & 50 & 40 & & 5.3 & 5.18 & 4.9 & 4.75 & 4.5 & 4.25 & 3.9 & 3.56 & 3.1 & 2.25 & & & & & 415 \\
\hline KDS.235+ & 1.5 & 2.0 & 50 & 40 & & 4.2 & 4.1 & 4.0 & 3.75 & 3.65 & 3.6 & 3.5 & 3.35 & 3.1 & 2.6 & 2.35 & \begin{tabular}{|l|l|}
2.01 .6 \\
\end{tabular} & 0.5 & & 415 \\
\hline KDS.314+ & 2.2 & 3.0 & 80 & 80 & 19.1 & 17.8 & 16.2 & 13.8 & 10.4 & & & & & & & & & & & 415 \\
\hline
\end{tabular}

Fig -8: Kirloskar Pump Product catalogue

The observation table for arrangement 4 shows that the mass flow rate of water is almost same for 100A as well as 150A. That's the reason why $\Delta T$ increased for $150 \mathrm{~A}$ reading as the mass flow was still the same. This mass flowing through the magnet is almost 2 times more than required flow rate for cooling. As per the calculations, laminar flow is sufficient for cooling the magnet, however available mass flow rate denotes just the start of turbulence region where heat transfer coefficient is good and thus good cooling will be provided.
Current cooler's cooling capacity is of 150 litres/hour. It was enough to perform experiment for a single magnet. But for 6 magnets we need to have cooler which can remove $7.325838 \mathrm{~kW}$ heat from water. So, for efficient performance we would have to have a cooler with increased capacity.

\section{0 litres $/$ hour $=0.04167 \mathrm{~kg} / \mathrm{s}$}

Suppose the cooler inlet temperature is $32^{\circ} \mathrm{C}$ and we want $\mathrm{O} / \mathrm{p}$ to be $10^{\circ} \mathrm{C}$, i.e $. \Delta T=22^{\circ} \mathrm{C}$

So, $Q=\stackrel{\circ}{m} . C_{p} \cdot \Delta T=0.04167 \times 4.187 \times 22=3.83839 \mathrm{~kW}$.

1. We either have to bring a cooler of increased capacity or

2. We have to compromise with cooling effect. $\Delta T$ of this cooler, i.e we won't get very cold water from cooler or

3. We would have to install 2 coolers of the same capacity to provide the necessary result

\section{CONCLUSION}

The best hydraulic connection is parallel combination of 4 groups (each group has 2 consecutive coils in series)

The present pump is almost supplying 1.5-2times the flow required for compensating heat loss and is thus of high capacity. To prevent unnecessary energy wastage, following light duty pumps are recommended:

[1]. KDS116+ with head of 14 or $16 \mathrm{~m}$ which provides 3.6, $3 \mathrm{lps}$

[2]. KDS $123+$ with head of 14 or $16 \mathrm{~m}$ Cooler is required to remove $7.326 \mathrm{~kW}$ heat from water

[3]. We either have to bring a cooler of increased capacity

[4]. We have to compromise with cooling effect $\Delta T$ of this cooler, i.e. we won't get very cold water of around 10 ${ }^{\circ} \mathrm{C}$ from cooler

[5]. We would have to install 2 coolers of the same capacity to provide the necessary cooling.

The amount of the cold water required depends on equipment geometry, flow velocity, viscosity, and hydraulic diameter, resistance to water flow, temperature rise, and specific heat of fluid and thermal conductivity of coolant. Also more surface area of wire contact with water due to more number of coil turns (10 in 1 pancake winding) improves heat transfer rate and thus improves the cooling of the magnet.

The power lost in the windings can be minimized by reducing the current $I$ and increasing the number of turns $N$ proportionally, or using thicker wire to reduce the resistance.

For $100 \mathrm{~A}$ current, $10.881 \mathrm{pm}$ water is required to cool all the 6 magnets by allowing a temperature rise of around $7.5^{\circ} \mathrm{C}$. Value of various characteristic parameters like flow rate of water required to maintain magnet at room temperature, pressure drop, temperature difference of inlet and outlet water, were calculated using theoretical calculations and were validated by comparing them with experimental results. 


\section{ACKNOWLEDGEMENT}

I wish to acknowledge and express my sincere thanks to $\mathrm{Mr}$ Sudhir Sharma, Mr Yagnesh Trivedi, Mr. Krishan Kumar Gotewal, Dr Vipul Tanna for their valuable guidance during this work. Special thanks to Mr. Amit Patel and Ms. Meenakshi Sharma who helped me in performing the experimental work

\section{REFERENCES}

[1]. Bage A, Ramsubramanian N, Thermal Analysis of Vacuum Chamber of Q-Machine, Advanced Materials Manufacturing \& Characterization, Vol 4, Issue 1, 2014

[2]. Th. Zickler, Basic design and engineering of normalconducting, iron-dominated electromagnets, CERN Accelerator School CAS 2009: Specialized Course on Magnets, Bruges, 16-25 June 2009, CERN-2010004, pp. 65-102

[3]. G. E. Fischer, Iron dominated magnets, $4^{\text {th }}$ Summer School on Particle Accelerators, Fermilab, Batavia, IL, 1984, M. Dienes and M. Month (Eds.), AIP Conference Proceedings 153(1987), pp. 1120-1227 [SLAC-PUB-3726(1985)]

[4]. National Institute of Standards and Technology (n. d) http://webbook.nist.gov/chemistry/fluid/

[5]. E.W. Lemmon, M.O. McLinden and D.G. Friend, "Thermophysical Properties of Fluid Systems" in NIST Chemistry WebBook, NIST Standard Reference Database Number 69, Eds. P.J. Linstrom and W.G. Mallard, National Institute of Standards and Technology, Gaithersburg MD, 20899, http://webbook.nist.gov, (retrieved October 11, 2015).

[6]. Your Chemical Engineering portal, myChemE (n.d) Retrieved from http://www.mycheme.com/

[7]. Design of cooling water system (2013, February 14) Retrieved from http://www.mycheme.com/design-ofcooling-water-systems/

[8]. Diniz, V. E. M. G. \& Souza, P. A., Four explicit formulae for friction factor calculations in pipe flow, WIT Transactions on Ecology and the Environment, 125, pp. 369-380, 2009

[9]. Meyrath, Todd, Electromagnet Design Basics for Cold Atom Experiments, Atom Optics Laboratory Center for Nonlinear Dynamics, University of Texas at Austin, 2003.

[10]. Kirloskar pumps (n. d) Retrieved from http://www.kirloskarpumps.com/pdf/offerings/distrib ution/Industry-Catalogue.pdf

[11]. Moore, Davis, Coplan Building Scientific Apparatus. Perseus Books, 4th edition

\section{BIOGRAPHIES}

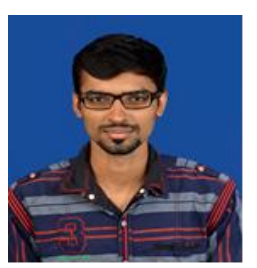

Nilesh Dama is currently a $4^{\text {th }}$ year Mechanical engineering student studying at K.J.Somaiya College of Engineering. $\mathrm{He}$ has research interests in the field of thermal sciences, cryogenics, and renewable energy.

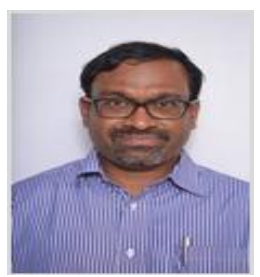

Dr. N. Ramasubramanian is Scientist SE working in Basic Plasma Sciences and is the Head of the Multi-cusp plasma division at the Institute for Plasma Research, Gandhinagar. 